\title{
Team Teaching Styles Utilized In Japan: Do They Really Work?
}

Harry F. Carley III, Matsuyama University, Japan

\begin{abstract}
This paper continues the debate over TT (team-teaching) benefits and detriments. TT has been utilized extensively in Japan in English Language instructional courses at the elementary and junior high school levels over the past 20 years. Although at times satirical, the author in all seriousness discusses TT and; its advantages and disadvantages in light of his experiences in various TT instructional environments. Team teaching can be a viable option for large or multiple classes; unfortunately, however, personality and cultural conflicts between instructors most often disallow any benefits that might be gained by the learners. In this paper, the author will discuss and share his specific experiences with TT over a fifteen year period in Japanese kindergartens, elementary schools, and junior high schools. Concluding remarks will analyze the TT approach between Japanese instructors in collaboration with their fellow Japanese teachers.
\end{abstract}

Keywords: Team Teaching; Co-teaching; EFL; ESL; Japan; TT

\section{INTRODUCTION}

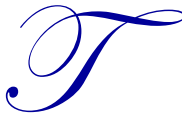

he concept of team teaching sounds ideal. Instead of one teacher, there are two. Thusly, both instructors can be working together toward a common goal of advancing the scholastic achievements of learners; the 'two for one, deal' of the teaching world.

Nevertheless, few would argue against that team teaching is a highly demanding task since it requires certain qualities from co-participants, including mutual trust and respect, time for planning and preparation, sharing roles and responsibilities, open-mindedness and flexibility, and support from principals and administrators (Buckley, 2000; Perry \& Stewart, 2005).

The theory of TT can be explained; you can have two teachers educating toward one common objective. But is this really so? As this article will explain the reality can be something different.

"In industrialized East Asian countries, the utilization of native speakers of foreign languages as assistants in team-taught classes has become an increasingly familiar, if not established component of national education curricula" (Meerman, 2003). As the author Jeon (2010),Since the 1980s, Asian countries such as Hong Kong, Japan, and Korea have started English co-teaching programs in their elementary and secondary schools by inviting thousands of native English speakers to teach with them. Team teaching as we have been led to believe is easily adaptable enough to be used at any level of education. All for good, good for all, or at least that may have been how it was originally envisioned.

In Western tradition and definition, the structure of collaborative teaching, or team teaching, involves two or more teachers cooperatively planning, instructing, and evaluating one or more groups in an appropriate instructional space and given length of time, so as to take advantage of the special competencies of the team members (Singer, 1964, cited in Buckley, 2000).

Does team teaching really work? Are there actual measurable results from having double the teachers compared to only a single instructor? From the author's personal experiences and teams that he has observed, he would have to say adamantly "no". The details of which roles to adopt, or what responsibilities to accept, will be 
dictated by matters including students' academic level, types of lesson, lesson duration and school culture.(Jang, Nguyen \& Yang, 2011). Additionally the researchers Jang, Nguyen \& Yang, (2011) on commenting about the advantages of TT state that;

In most Asian countries, team teaching of native English speaking (NES) and non-native English speaking (NNES) teachers in ESL/EFL classrooms has been popular over the past decades. The main rationale behind this coordinative approach is that this unique team with different backgrounds and expertise can complement each other to maximise efficiency in their common mission of language teaching. Therefore, this joint collaboration in ESL/EFL teaching of NES and NNES teachers is believed to present significant benefits for both teachers and students in addition to offering a deeper insight into cross-cultural teamwork. However, there are a number of issues concerning the roles between NES and NNES teachers, particularly in addressing the questions: who is better and who is the ESL/EFL specialist in charge.

As for the authors early years in Japan, he was employed as an ALT (Assistant Language Teacher) who visited Japanese schools and taught along side JTE's (Japanese Teachers of English). He was in this position been for approximately twenty years. Regrettably, at no time did he feel that his 'team' had fulfilled the objective that they were tasked with. The EFL level of the students did not benefit from their melding of minds in any obvious form. Instead it may have had a degenerating effect due in actuality that each of them (JTE/ALT) had conflicting ideas as to how EFL should be taught.

His experiences with team teaching in ALT Japanese classroom environments has consisted of teaching at the junior high level, elementary, and kindergarten/nursery school levels. Each of these teaching scenarios differed in the role that he served as an ALT. What these three situations did have in common though, was that EFL classes in a team teaching format were all held infrequently (once/twice a month). Summarily, in many instances, it didn't seem to matter if a native speaker was present or not.

The following includes a brief description, his personal experiences and observations of each of the three;

\section{JUNIOR HIGH SCHOOL}

The JTE (Japanese Teacher of English) did most if not all of the planning and most of the prep work for the classes. He tried to assist in any way he could. Unfortunately at most JHS, he only interacted with each individual class once or twice a month. He did not know what page of the text they were on until the day that he arrived. Planning before teaching together is a vital aspect of the process when goals need to be verbalized, negotiated and rationalised (Stewart, 2005).

Overall though TT can have a positive impact on students though as Meerman states when describing the interaction between Alts and JLTs (Japanese Language Teachers);

Both ALTs and JLTs perceive efforts to develop team teaching as a professional practice as having a positive impact on lesson content. Sharing and documenting experiences are important for the long-term refinement of teamteaching; when ALTs feel their contributions are valued and will endure following their departure from Japan, they are likely to make a greater personal investment in preparing future lesson content (Meerman, 2003)

Unfortunately in most cases that the author was aware of this was not necessarily the eventuality. The EFL abilities of the JTE tended to vary widely. In the past 20 some years, he can say that he has witnessed their abilities improve almost to the point of considering whether he was really needed or not. The JTE may explain what was going on in the class for that day and what was required of him. In the JHS situation it basically came down to "DWHWT" (Do What He Was Told). The texts that were and are currently in use in Japanese junior high schools all have supplementary workbooks, listening CD's and/or cassette tapes. In a few cases video sets were also provided by the publishers. With all these supplementary materials available the added cost of having a native speaker could certainly be disputed. 


\section{ELEMENTARY SCHOOL}

At the Japanese elementary school level of EFL teaching the conditions were vastly different from JHS. This was an area where the situation has seen the most advancement. Twenty years ago, his attendance at the elementary schools was similar to that of the JHS. The one exception here being was that a vast majority of elementary school teachers involved with EFL instruction were at a low level of EFL themselves. Lesson planning and execution of the plans tended to have vast amounts of confusion and uncertainty of just what they were trying to accomplish. The future direction of the EFL classes, if any, was extremely muddled. Lessons tended to be thought out one class at a time with total disregard for any continuity in the language building structure.

In the past few years, as his language teaching abilities grew, their positions (ALT/JTE) in the elementary schools become altered. He could describe his duties in a Japanese elementary school to be totally opposite to that of the JHS. He did all planning, preparation, and implementation of the lessons. The JTE had no duties or requirements and were actually there to assist him, the ALT. It was a total reversal of roles. Additionally, there had been numerous times where the JTE was not present, or just faded in and out of the classroom to attend other duties, thusly he taught solo (a team of one?).

\section{KINDERGARTEN/NURSERY SCHOOL}

This involved again another variant of the team teaching description. In this situation the JTE (if they could be called that) were in all actuality nothing more than the nursery school teacher for that particular group. She may or may not have processed any English language speaking abilities or teaching skills but then again it didn't really matter. Their sole purpose for EFL classes was to keep the young scholars under control as best possible. Again another situation where ALL preparation, presentation, and many times clean up was the author's sole responsibility. shaped up.

So from an Assistant Language Teacher's view this is how the three typical team-teaching formats have

Additionally before concluding he would like to mention the team teaching scenario between Japanese teacher and Japanese teacher. Team teaching has been vigorously utilized in this concept for the very same reason as ALT's and JTE's have been teamed together, all in the hopes of raising academic achievement.

\section{JAPANESE AND JAPANESE TT}

Problems with team teaching between Japanese teachers basically seem to stem from simple human behavior; and have taken three forms:

- Japanese teachers of similar age and skills.

- $\quad$ One older Japanese teacher and one younger.

- $\quad$ Two Japanese teachers regardless of age but with vastly different skills and ideologies.

Enthusiasm and a positive attitude are essential when two different teachers are engaged in team work (Friend, 2008). One teacher's reluctance or indifference to collaborate affects the other teacher and also hinders students' learning (Jang, Nguyen \& Yang, 2011). Welch (1998) stated that some barriers to successful collaboration include differences in educational concepts, a pragmatic approach and personal attitudes.

The first form is actually the one he has tended to come into contact the most. It basically reflects the overall Japanese society with many older veteran teachers and very few new teachers entering the profession. In this team teaching situation since both are veteran teachers, both want to be the 'captain' of the team. A worst case scenario which actually happened a few years ago - two teachers got upset with each other, refused to work with each other, and did not converse with each other, unless it was absolutely necessary, for an ENTIRE academic year. The team had thusly been divided into half, each member going their own way with little or no consultation from the other. A sad state of affairs for all involved. If a good partnership exists, the question of who is doing more or less will probably not become a contentious issue as the focus is on a team result and both partners would 
subconsciously strive for a fair division of labour (Carless, 2006). Always savvy students can read an uncomfortable and tense relationship and may use a rift between teachers to manipulate a situation to their advantage (Sileo, 2011)

In the second form the assignment of team captain was solved since the older more senior of the two Japanese teachers naturally assumed command. Of the three cases among Japanese team teaching this is the one situation where TT actually has a chance of success. When planners thought up TT this seems to be what they had in mind. Regrettably he has yet to see this occur. In almost all cases the captain may become extremely dominant and actually develop a 'team owner' type of mentality whereas the junior teacher has an instructional life of hell. The junior member merely does the best that they can and prays for a day when the team is disbanded or that they are simply traded to another team.

The final example of Japanese team teaching is nothing more than a team in chaos. Both members differ in their teaching approaches and beliefs. Not beneficial for the teachers and especially not advantageous for the learners, whether the subject is English or environmental science. Most importantly, both teachers need to be flexible and willing to accept the fluidity of content roles in the partnership (Stewart, 2005). From his personal observations, this is actually the TT that occurs most frequently. Again as mentioned earlier, the reason for this dysfunction of TT simply has to due with human nature. Each instructor assumes that they possess the more beneficial of the teaching skills. Two players vying for the same position on a sports team if it were.

\section{CONCLUSION}

So what are recommendations for TT, based on real-life classroom experiences? Team-teaching has not proven to be an effective teaching tool, at least in the opinion of this author. It should be phased out and teams dissolved. The recent proliferation and growth of large-scale, nationally funded teacher 'exchange' programs testifies to an intensifying effort throughout the region to improve students' linguistic competence, communication skills and cross cultural awareness to facilitate integration into a rapidly shrinking world (Meerman, 2003). Has this been money and time well spent though? This is an area where much research is still to be collected and analyzed.

TT or Co-teaching has been cited as extremely beneficial by many scholars and researchers. Research has shown that team teaching is an effective way of constructing deep learning of concepts while learning alternative ways to teach the same subject-matter (Jang, 2006). "Specifically, compared to the traditional classroom where the non-native English teacher alone was responsible for all of the instruction process, a collaborative team work in which language teachers with different linguistic and cultural backgrounds is able to better respond to students' need or interests" (Jui-min Tsai, 2007). The author states the actuality of present day research into TT or Co-teaching; Jeon, (2010).

Despite its pedagogical advantages mentioned above, the instructional framework of co-teaching and the dynamics of interaction between native and non-native teachers have not been closely explored, especially in a classroom setting. For example, much research on co-teaching in the EFL context has been quantitative in nature, focusing teachers' and students' reactions in relation to its advantages and disadvantages.

In close to twenty years as an ALT, being in countless elementary and junior high schools, even being married to a Japanese elementary school teacher, in not a single example of team-teaching has he witnessed teamteaching as it was supposedly envisioned. A single teacher working at full capacity and without interference is able to provide more benefits to learners than that of a two teachers in conflict suppressing the abilities of learners. The tension that may exist between team members can be very evident to the learners that they are supposedly assisting and thusly providing benefit to no one. As in other relationships, when things go wrong the partners need an opportunity to sit down and address issues in a structured manner (Sileo, 2011). All too often the personal pride of teachers, along with academic position within the learning environment, age, and in the instances of cultural differences with regards to ALTs and JTEs hinder and may actually eliminate and gains sought in TT. In this author's opinion, this potential turmoil adds no enlightenment to the education process and the negativity outscores any benefits in most cases. The author Jang (2006) states that; "It is suggested that the teachers should be encouraged to drop outdated concepts, to learn and to continually grow". "The key, of course, lies with teachers themselves undertaking this more actively; otherwise educational reform cannot achieve its goals". 
As this article has proven though the actuality in educational environments tends to differ from data and research collected. "Effective communication is key to navigating professional relationships, whether teachers are thrown together or have time to get to know each other" (Sileo, 2011). The very human nature of individuals, busy teaching schedules, and other difficulties contrasts against the stated objectives of TT.

\section{AUTHOR INFORMATION}

Harry F. Carley III, The author has been a foreign resident of Japan for almost 25 years. He holds M.A.'s in English Language Teaching and Education Technology. He has had experience teaching at all levels of the Japanese education system, from very young children to adults. He has lectured all over Japan and in numerous foreign countries. His research interests includes establishing primary school English education in Japan and the application of technology to teaching. Currently he is a lecturer at Matsuyama University, Ehime, Japan. E-mail: pm333@ric.hi-ho.ne.jp

\section{REFERENCES}

1. Buckley, F. J. (2000). Team teaching: What, why, and how. Thousand Oaks, CA: Sage.

2. Carless, D. (2006). Collaborative ESL/EFL teaching in primary schools. ELT Journal, 60(4), 328-335.

3. Friend, M. (2008). Co-teaching: A simple solution that isn't simple after all. Journal of Curriculum and Instruction, 2(2), 9-19.

4. Jang, S.H., Nguyen B.H. \& Yang, Y. (2011). Enhancing Pedagogical Roles of ESL/EFL Native and NonNative Teachers through Team Teaching: How to Make this 'International Partnership' Successful. The International Journal of Learning, Volume 17, Issue 9, pp.249-258.

5. Jang, S-J. (2006). Research on the Effects of Team Teaching upon Two Secondary School Teachers. Educational Research, v48 n2 p177-194.

6. Jeon, In-Jae. (2010). Exploring the co-teaching practice of native and non-native English teachers in Korea. English Teaching, 65(3), 43-67.

7. Meerman, A.D. (2003). The Impact of Foreign Instructors on Lesson Content and Student Learning in Japanese Junior and Senior High Schools. Asia Pacific Education Review. Volume 4, Number 1, 97-107, DOI: $10.1007 / \mathrm{BF} 03025556$.

8. Perry, B., \& Stewart, T. (2005). Insights into effective partnership in interdisciplinary team teaching. System, 33, 563-573.

9. Sileo, J.M. (2011). Co-Teaching: Getting to Know your Partner. Teaching Exceptional Children; May/Jun 2011, Vol. 43 Issue 5, p32.

10. Stewart, T. (2005). Interdisciplinary team teaching as a model for teacher development. TESL-EJ Top, 9(2) 45-58.

11. Tsai, Jui-min. (2007). Team teaching and teachers' professional learning: Case study of collaboration between foreign and Taiwanese English teachers in Taiwanese elementary schools. Unpublished doctoral dissertation, The Ohio State University, $\mathrm{OH}$.

12. Welch, M. (1998). Collaboration: Staying on the bandwagon. Journal of Teacher Education, 49(1), 26-37. 
NOTES 